\title{
UNCERTAINTIES IN ANALYSING THE TRANSFERABILITY OF THE GENERIC SLUM ONTOLOGY
}

\author{
J. Pratomo ${ }^{\text {a }}$, M. Kuffer ${ }^{\mathrm{a},}{ }^{*}$, J. Martinez $^{\mathrm{a}}$, D. Kohli ${ }^{\mathrm{a}}$ \\ ${ }^{a}$ Faculty of Geo-Information Science and Earth Observation (ITC), University of Twente, PO Box 217, 7500 AE Enschede, The \\ Netherlands - (j.pratomo, m.kuffer, j.martinez, d.kohli)@utwente.nl
}

KEYWORDS: GSO, Uncertainties, Transferability, Qualitative, Quantitative

\begin{abstract}
:
The Generic Slum Ontology (GSO) was developed to assist the detection of slums using Geographic Object-Based Image Analysis (GEOBIA). When applying the GSO locally, uncertainties exist in slum detection and transferability. Slums often have fuzzy boundaries and different ways to conceptualise. This study focuses on inherent uncertainties when analysing the transferability of the GSO across space, time and conceptualizations in the city of Jakarta, Indonesia. To measure the transferability of the GSO, we developed quantitative and qualitative indicators in multi-temporal Pleiades imagery (2012-2015) of two purposely-selected subsets. This framework allows assessing whether the developed ruleset is transferable across different spatial and temporal images. We applied two classification stages: background removal with a low scale parameter (SP) followed by slum extraction with a coarser SP. Both quantitative and qualitative indicators showed limited spatial and temporal transferability. Three sources of uncertainties can explain this result. First, the static concept of the employed ruleset and dynamic changes of slums. Real-world objects evolve over time, but their description remains static. Second, the gap between the real world (subjective conceptualization of objects) and image domain (quantitative values). For instance, the roof materials of slums (i.e. asbestos) have a similar spectral property with parking lot (from concrete), which resulted in misclassification. Third, the use of references data from local experts and municipal data introduce uncertainties that related to local ground knowledge and politics of slum declarations. Thus, this research contributes to the development of transferability measurements for the GSO and the understanding of underlying uncertainties.
\end{abstract}

\section{INTRODUCTION}

\subsection{Generic Slum Ontology (GSO)}

The Generic Slum Ontology was developed by Kohli, Sliuzas, Kerle, and Stein (2012) to assist the detection of slums in the GEOBIA domain. The GSO consist of three spatial levels, i.e., object, settlement, and environs (Kohli et al., 2012). At the environs level, Kohli et al. (2012) characterise slums by their location and neighbourhood characteristics; slums are often located in hazardous areas that may be close to employment opportunities. Meanwhile, on the settlement level, slums are characterised by their shape and density, where they often follow physical features, e.g. elongated settlements along rivers (Kohli et al., 2012). Lastly, at the object level, slums are characterised by building characteristics and access networks. However, not all slum characteristics can be determined by satellite imagery. Thus, for indicators that are not directly detectable from imageries, Kohli et al. (2012) recommended combining various other attributes that could act as proxy variables, i.e. roof type and building footprint area.

To implement the GSO in slum detection has three challenges (Pratomo, 2016). First, slums have unique spatial and temporal characteristics compared to formal areas, but can show considerable diversity within a city and even within a settlement (Kuffer, Pfeffer, \& Sliuzas, 2016). Second, slums have different definitions depending on the context. For this challenge, Kohli et al. (2012) recommended adopting the GSO to the local context. Third, due to the dynamics of slums, the GSO needs to be adapted to perform in multi-temporal images.

\subsection{Transferability}

Transferability, as mentioned by Kohli, Warwadekar, Kerle, Sliuzas and Stein (2013) refers to the capability of a method to result in comparable outputs with minimum adaptations, when applied in different spatiotemporal conditions. Selecting a single evaluation method to measure transferability is difficult (Bamberger, 2012). The usage of mixed-methods can combine the strength of quantitative and qualitative methods, which can overcome their respective weaknesses (Bamberger, 2012).

For quantitative methods to measure the transferability, Tuanmu et al. (2011) suggested three indicators to assess the transferability of a model. First, the model should result in a similar performance under different temporal conditions. Second, the model should result in a similar performance in various places. Third, the models should lead to similar spatial patterns (Tuanmu et al., 2011). Meanwhile, the usage of qualitative methods in measuring transferability aims to enhance, complement and follow up unexpected results from quantitative methods (Harwell, 2011). A study from Sori (2012) proposed several qualitative indicators, such as reliability, efficiency, utility and generality, and validity. 


\section{MATERIALS AND METHOD}

\subsection{Study Area}

Jakarta, the capital city of Indonesia, is inhabited by 30 million people within its metropolitan area (Demographia, 2015). The inability of local authorities to provide affordable housing has forced many low-income citizens to live in slums. To increase the quality of settlements, the national government of Indonesia developed policies to achieve the $100-0-100^{1}$ target by 2019 (UN-Habitat, 2014). Therefore, to monitor the achievement of this target, reliable data regarding slums is crucial.

Monitoring the dynamics of slums in the study area faces three main sources of uncertainties. First, the different definitions used to characterise slums (Pratomo, 2016). For instance, the Indonesian Central Board of Statistics (BPS) (2013) characterise slums by four indicators, i.e., lacking access to clean water, poor building materials, poor sanitation, and inadequate living space. Meanwhile, a different definition is used by the Ministry of Public Works and Public Housing (2014), using six characteristics, i.e., poor disposal, low coverage and poor quality of access network, an area inundated during rain, poor quality of water sources, high density and poor quality of settlements. The second uncertainty in monitoring slums refers to different levels to measure slums (Pratomo, 2016), commonly either on settlement level or household level. According to the official data obtained from the Department of Building and Settlements (DKI, 2014), the extent of slum settlements in Jakarta shows a decreasing trend between 2004 to 2013 (Figure 1). Meanwhile, the number of slum inhabitants increased between 1997 and 2013 (Department of Building and Settlements DKI, 2014). This fluctuation is partially due to the different levels used to measure slum extent and population.

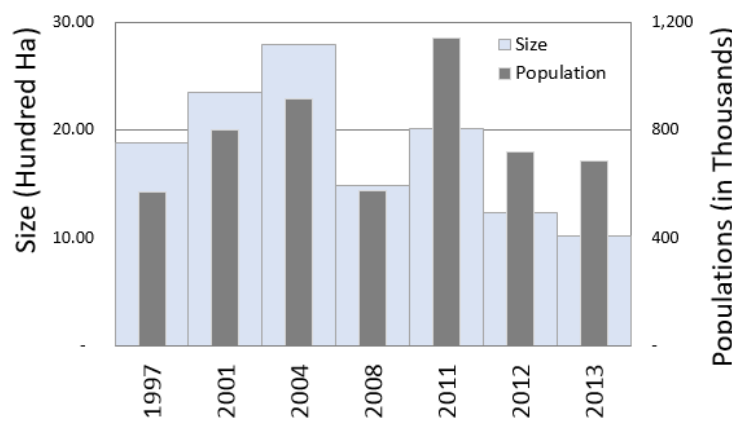

Figure 1. Trend of Slums in Jakarta (Pratomo, 2016)

The third source of uncertainties in monitoring slums is due to the existence of kampungs. This housing typology appeared in Jakarta more than half a century ago when the formal planning institutions were not established (Rukmana, 2008). To some extents, Kampungs are informal settlements, which share similar characteristics with slums, e.g., high density and unorganised layout. However, we cannot categorise all kampungs as slums, since many kampungs' residents have a formal ownership on land.

\footnotetext{
1 This programs aimed to achieve $100 \%$ access of clean water, $0 \%$ slums and $100 \%$ access to sanitation.
}

\subsection{Data Sources}

2.2.1 Image Selection. Multitemporal Pleiades imageries from the year 2012 to 2015 were used in our research. The spatial resolution of these images is 0.5 meters (after pansharping). We selected one image for each year with cloud coverage of less than $10 \%$. All images were radiometrically corrected. To analyse the transferability across different spatial conditions, we selected a subset that has variations in its spatial characteristics. The chosen area was the Tebet District in Jakarta (Figure 2). The subset size was 21 square kilometres. This district was selected due to three factors. Firstly, various urban features, from high-class residential, CBD to slums are located in this district. Secondly, a river passes through the district; regular floods occur here, and slums are often found near rivers. Lastly, various typologies of slums exist in this district, e.g., slums located on the riverbank and near the railroad. For the accuracy assessment, we employed groundtruth data collected in 2015 combined with slum delineations by the local experts.

2.2.2 The usage of ancillary data. To assist slum detection in GEOBIA, we employed several ancillary data (Table 1). The utility of combining VHR imagery with ancillary data for slum detection was demonstrated by Netzband (2009), Sori (2012), and Kohli et al. (2013).

\begin{tabular}{|l|c|l|}
\hline \multicolumn{1}{|c|}{ Data } & Year & \multicolumn{1}{c|}{ Source } \\
\hline Google Earth Image & 2013 & Google Earth \\
Google Street Map & 2013,2015 & Google Streetmap \\
Land use planning & 2014 & Govt of Jakarta \\
River, waterbody & 2015 & Openstreet Map \\
Road/rail network & 2014 & Openstreet Map \\
Socio-Economic & 2010,2015 & Statistical Bureau \\
District Boundary & 2014 & Govt of Jakarta \\
Slums neighbourhood & $2007-2013$ & Govt of Jakarta \\
\hline
\end{tabular}

Table 1. Ancillary Data

\subsection{Slum Detection in GEOBIA}

2.3.1 Formulation of the Local Ontology. To develop the local slums ontology (LSO), we conducted topic-focused interviews (Groenendijk \& Dopheide, 2003) with five local experts with experience on slum issues in Jakarta having different backgrounds. These were two experts from the government (central and local), one expert from an NGO, and two experts from consultants. During the interviews, experts indicated the local characteristics of slums and delineated the slum locations in the subset image.

2.3.2 Development of the ruleset. In our study, we developed two rulesets. The first ruleset was developed via a local adaptation of the GSO. The second ruleset was, however, developed based on the local slum characteristics listed by the experts, here called local slum ontology (LSO). The different characteristics of slums were then linked to image characteristics of slums, e.g., tone, shape, size, association and texture (Table 2).

\begin{tabular}{|l|l|c|c|}
\hline \multicolumn{1}{|c|}{ Real-world } & \multicolumn{1}{|c|}{ Image Domain } & GSO & LSO \\
\hline $\begin{array}{l}\text { Located on } \\
\text { riverbank/railroad }\end{array}$ & $\begin{array}{l}\text { Association: Distance } \\
\text { to river/railroad }\end{array}$ & $\sqrt{ }$ & $\sqrt{ }$ \\
\hline $\begin{array}{l}\text { Close to economic } \\
\text { hotspot }\end{array}$ & $\begin{array}{l}\text { Association: Distance } \\
\text { to CBD/industry }\end{array}$ & $\sqrt{ }$ & $\sqrt{ }$ \\
\hline Built in illegal land & Ancillary: land use & - & $\sqrt{ }$ \\
\hline
\end{tabular}




\begin{tabular}{|l|l|c|c|}
\hline \multicolumn{1}{|c|}{ Real-world } & \multicolumn{1}{c|}{ Image Domain } & GSO & LSO \\
\hline Irregular pattern & Shape: Irregular & $\sqrt{ }$ & $\sqrt{ }$ \\
\hline High density & Texture: GLCM & $\sqrt{ }$ & - \\
\hline $\begin{array}{l}\text { Absence of green } \\
\text { space/ vegetation }\end{array}$ & $\begin{array}{l}\text { Association: vegeta- } \\
\text { tion/green space }\end{array}$ & $\sqrt{ }$ & - \\
\hline Irregular roads & Shape: Irregular & $\sqrt{ }$ & $\sqrt{ }$ \\
\hline Small building size & Size: small & $\sqrt{ }$ & $\sqrt{ }$ \\
\hline Poor roof materials & Tone: Asbestos, iron & $\sqrt{ }$ & $\sqrt{ }$ \\
\hline Poor sanitation & Ancillary: Sanitation & - & $\sqrt{ }$ \\
\hline
\end{tabular}

Table 2. Application of Real-world into Image domain

2.3.3 Selection of the test area. To test the ruleset that was developed from the GSO and LSO, we purposively selected two test areas in Tebet District (Figure 2). For the first area, we selected an area where local experts had a relatively similar agreement on the slums extent. For the second sample, we selected an area where local experts had very different slum delineations. To reduce the computation time, we selected relatively small test areas, of 1 square kilometre.

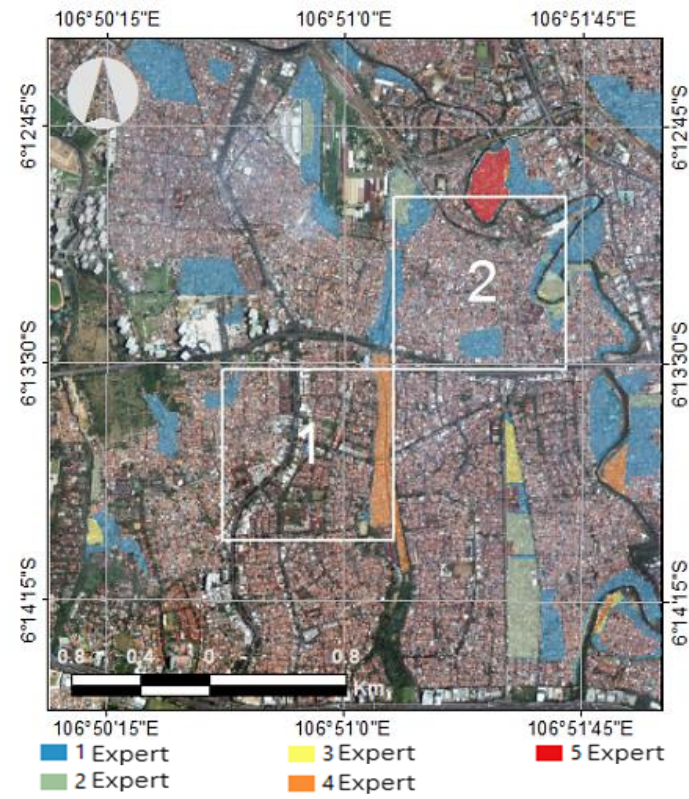

Figure 2. Selection of the test area

2.3.4 Segmentation. Among various segmentation algorithms, we selected the multi-resolution segmentation, being widely used due to its capability to create homogeneous objects based on user-defined thresholds (Baatz \& Schäpe, 2000). Some studies demonstrated the usage of multi-resolution segmentation in the slums domain, e.g., Kuffer, Barros, and Sliuzas (2014), and Kohli, Kerle, and Sliuzas (2012).

Within multi-resolution segmentation the setting of an appropriate scale parameter (SP) is necessary (Drăguț, Tiede, \& Levick, 2010). The SP controls the heterogeneity of an object, and its value correlates with the object size (Baatz \& Schäpe, 2000). The major drawback of the usage of multi-resolution segmentation is the commonly employed trial-and-error approach in selecting an appropriate SP (Whiteside, Boggs, \& Maier, 2011). To facilitate the estimation of an appropriate SP, Drăguţ et al. (2010) proposed a tool for Estimation of Scale Parameter (ESP), based on the idea of the Local Variance from Woodcook and Strahler (1987). In our study, we employed two levels of segmentation. At the first level, we employed a low $\mathrm{SP}$, with equal value for the smoothness and compactness parameter. The image objects resulting from the first level of segmentation were used as an input for background extraction. For the second level segmentation, we employed coarser SP, where the value was obtained from ESP.

2.3.5 Classification. Similar to the segmentation process, also for classification we employed a two-level approach. For the level 1 classification, we focused on extracting background classes, which are vegetation, road, railroad and river. For vegetation, we used the NDVI. The features roads, railroads and river, were classified using vector layers obtained from Openstreet Map (OSM). After we had extracted the background classes, the remaining unclassified image objects were segmented again with a coarser SP (see 2.3.4). Next, we employed two rulesets, i.e., from GSO and LSO.

\subsection{Transferability Measurements}

To measure transferability, we employed both quantitative and qualitative measurements. For quantitative measurements, we adopt the transferability framework of Tuanmu et al. (2011). For the qualitative measurement, we adopted indicators from Sori (2012).

2.4.1 Quantitative measurements. We measured the spatial and temporal transferability according to the resulted accuracy from the classification process. The ruleset is transferable, regarding spatial transferability, if it produces a similar accuracy with minimum adaptation when it is applied to a different location (image of the same date) (Figure 3). Meanwhile, for temporal transferability, similar accuracies should be obtained when implementing the ruleset to an image of a different date (at the same place) (Figure 4). Regarding spatiotemporal patterns, rulesets are transferable if they result in similar spatiotemporal patterns (Figure 5). For analysing the spatiotemporal patterns, we compared the spatial metrics of the extracted slums (from the GSO and LSO). We used the Unplanned Settlement Index (USI) developed by Kuffer et al. (2014), as indices.

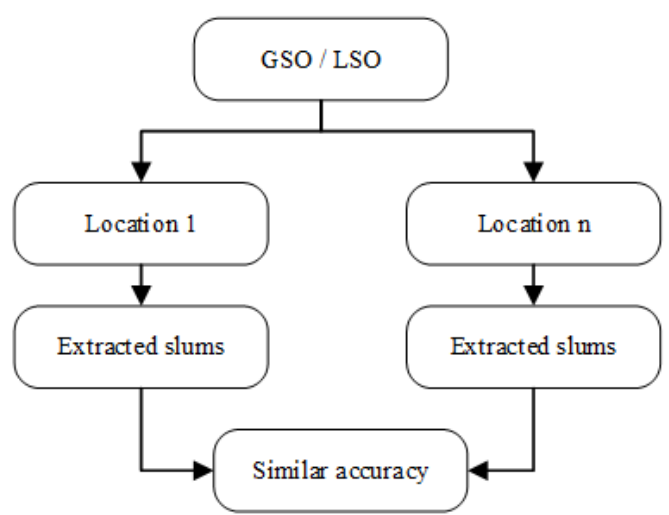

Figure 3. Spatial Transferability Framework 


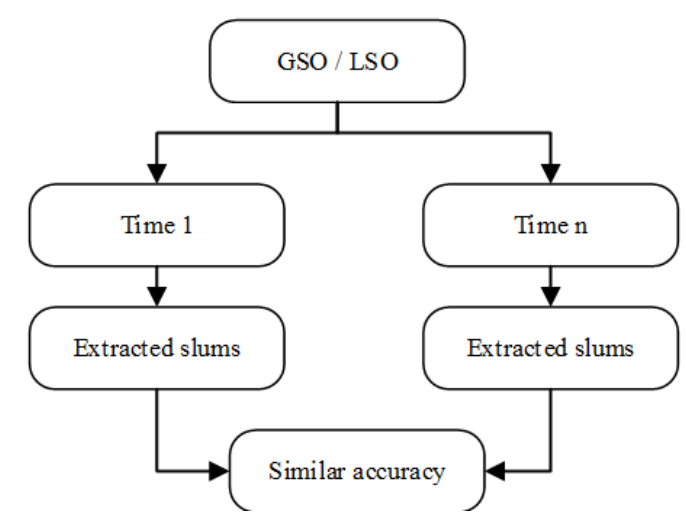

Figure 4. Temporal Transferability Framework

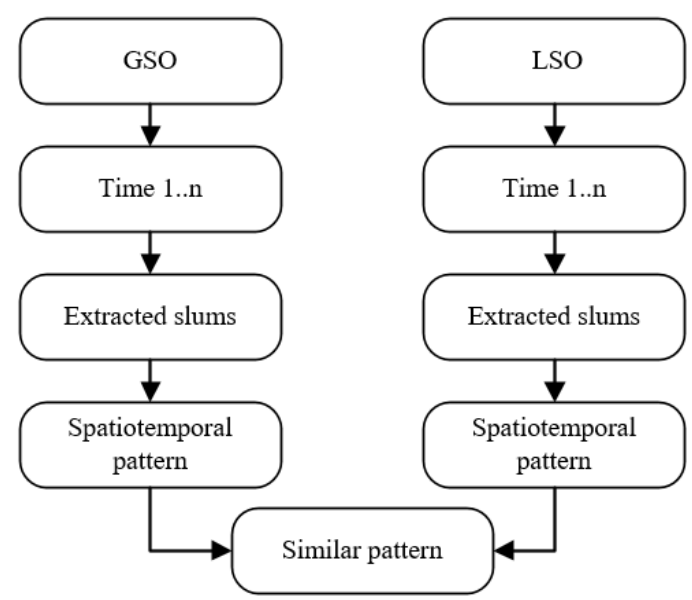

Figure 5. Spatiotemporal Transferability Framework

Three accuracy measurements were used to measure the spatial and temporal transferability, which are Overall Accuracy (OA), Kappa Index and quality of classification. For the quality of classification, the number of True Positives is compared with every possible result (True Positive, False Positive, and False Negative) (equation 2), as suggested by McKeown and Cochran (1999). The TP, FP and FN are defined by comparing the classification results from automated (GEOBIA) and manual delineations (from local experts).

$$
\text { Quality }=100 * \frac{T P}{(T P+F P+F N)}
$$

$$
\begin{aligned}
& \text { where } \quad \text { TP }=\text { True Positive } \\
& \text { FP }=\text { False Positive } \\
& \text { FN }=\text { False Negative }
\end{aligned}
$$

For the spatiotemporal comparison, we used spatial metrics to compare the classification results. Among various spatial metrics that may be utilised, we used Landscape Division Index, Patch Density, Aggregation Index, Shannon's Evenness Index, and Contagion Index.
2.4.2 Qualitative measurements. We employed two transferability indicators suggested by Sori (2012). For the first indicator, we measured the transferability according to the utility. A high utility is obtained when a large number of criteria (from the GSO and LSO), can be transformed into the image domain. For the second indicator, we used generality. The ruleset is transferable if the number of required adaptation for extracting slums is limited.

\section{RESULTS AND DISCUSSION}

\subsection{Slums Detection}

We detected the slums according to the GSO and LSO in the first and second area (Figure 6). For the 2013 data, we employed two temporal imageries. The 2013-2 data is applicable in both area, while the 2013-1 is only applicable in the first area due to high cloud cover in the second area.

3.1.1 GSO in the first area. Slums are reducing between 2012 and 2015 (first column, first to the fifth row). The slums can be divided into two patches, an eastern and western patch. Both patches show different slum extents. Some misclassification occurred in the west patch, which is a car park with similar spectral properties. This shows the uncertainties that resulted from transforming the real world characteristics of slums (i.e. poor roof materials), into image domain characteristics (i.e. tone of the roof) (see Table 2).

3.1.2 LSO in the first area. Slums that were detected resulted in a smaller area (second column, first to the fifth row) compared to the slums delineated by the experts. In the western part, only small areas of slums were detected. Although we can notice irregular patterns in the eastern parts, this area is not detected as slums, because of using the land tenure as an indicator. The use of references data from local experts (see Figure 2) and municipal data (see Figure 1) introduce uncertainties that relate to local ground knowledge and politics of slum declarations.

3.1.3 GSO in the second area. For the second area, we excluded the image obtained from May 2013 (2013-1) due to high cloud cover (Figure 6). Detecting slums in this area is more challenging since slums and non-slums are more difficult to distinguish. In general, slums that are located near the railroad stretching from south to north. They were changing between 2012 to 2015. A similar result is obtained for the slums that are located on the riverbank in the eastern parts. Meanwhile, slum areas along the railroad from east to west are relatively stable.

3.1.4 LSO in the second area. We can notice relatively stable slum locations in the western part (fourth column, row 1, 3-5). Only small changes occurred in this location during 2012 and 2015. A similar location, which is more stable, is found nearby the railroad in east-west direction. This pattern apparently is consistent with the results from the GSO. Outside this location, we also found slum areas that are relatively stable on the riverbank in the north side of the area. 

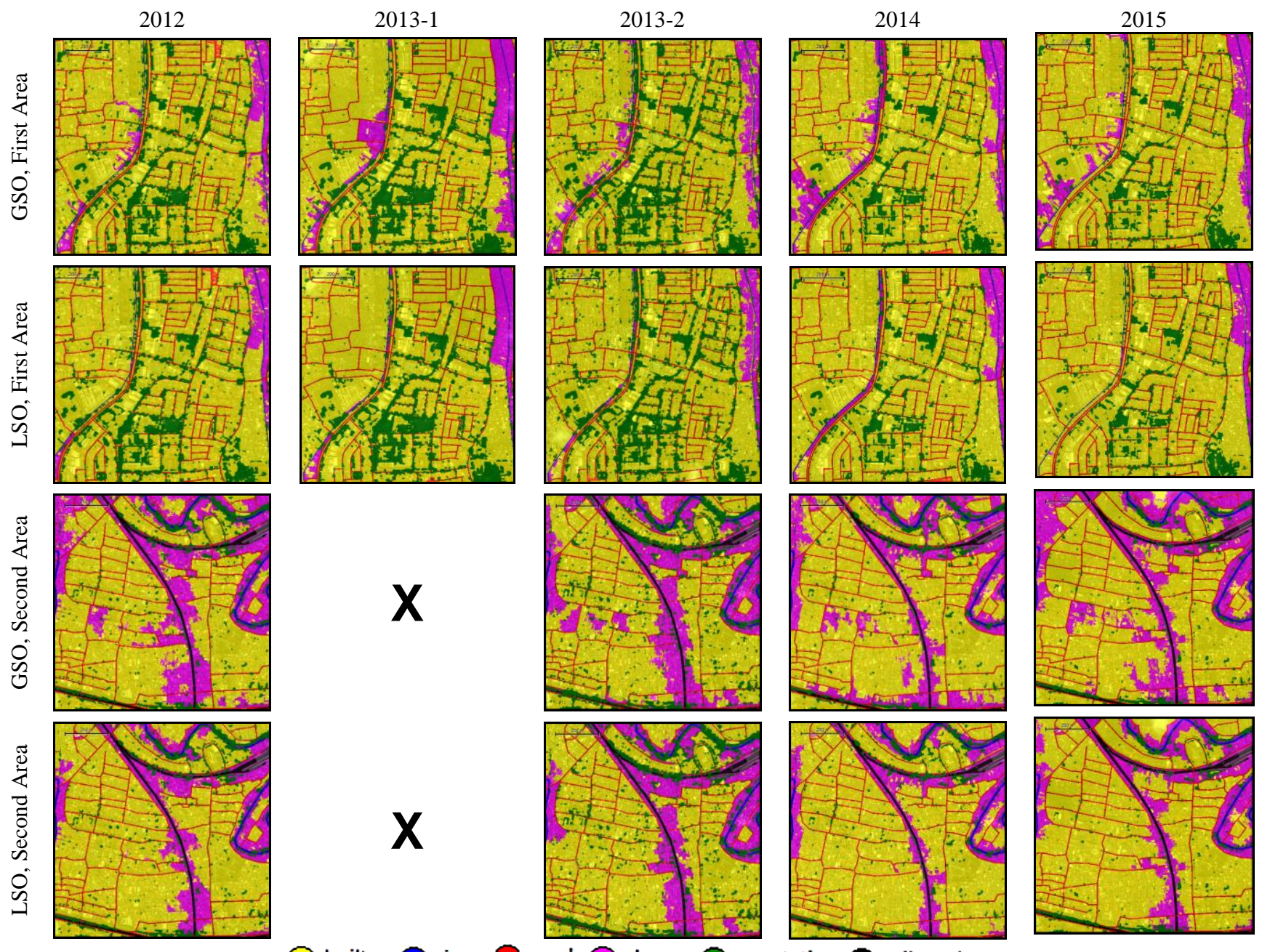

Figure 6. Result of Slum Detections

\subsection{Quantitative Measurements of Transferability}

3.2.1 Spatial Transferability. The ruleset should result into similar accuracies when applied in different areas. Hence, the difference of accuracies should be as low as possible. Accuracy results can be seen in Figure 7.

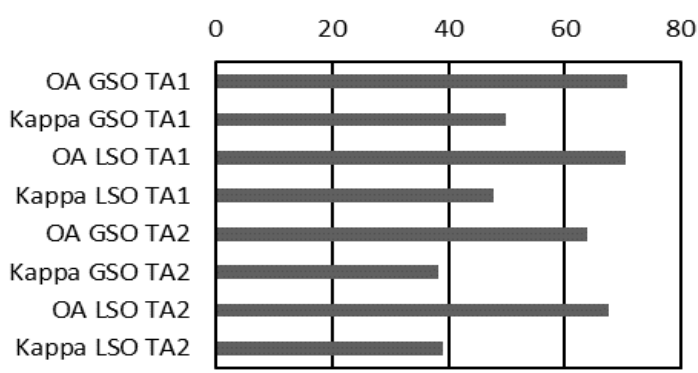

Figure 7. Confusion matrix-based accuracy (average)

For OA, the GSO resulted in a higher value compared with the LSO in the first area (TA1). For the second area (TA2), both rulesets led to the same result. We also noticed that the OA and kappa for this area are higher, compared with the first area. For the quality of classification (equation 2), the different concepts and delineations of slums (Table 2 and Figure 2) made it difficult to decide on the actual slum boundary (Figure 8). As a result, we found that the quality obtained from GSO and LSO is low (Table 3).

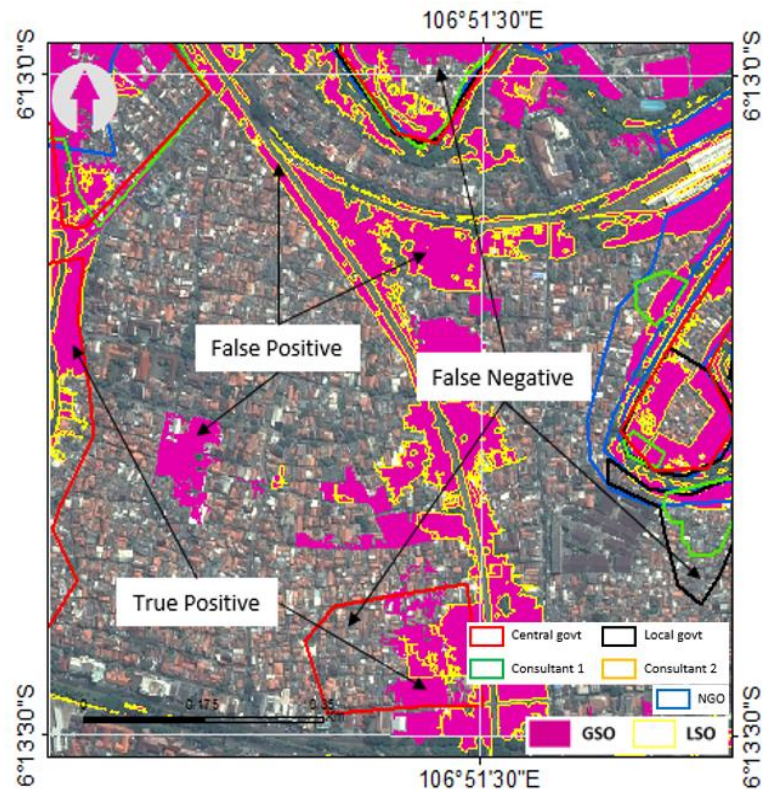

Figure 8. Automated and Manual Slum Extraction (area 2) 


\begin{tabular}{|c|c|r|r|r|}
\hline $\begin{array}{c}\text { Area, } \\
\text { ruleset }\end{array}$ & $\mathrm{TP}\left(\mathrm{m}^{2}\right)$ & \multicolumn{1}{|c|}{$\mathrm{FP}\left(\mathrm{m}^{2}\right)$} & $\mathrm{FN}\left(\mathrm{m}^{2}\right)$ & $\mathrm{Q}(\%)$ \\
\hline 1, GSO & $40,776.5$ & $14,508.1$ & $74,634.2$ & 31.39 \\
1, LSO & $34,809.8$ & $4,696.3$ & $80,600.9$ & 28.98 \\
2, GSO & $85,331.7$ & $145,663.6$ & $106,208.9$ & 25.31 \\
2, LSO & $52,969.3$ & $99,405.9$ & $138,571.3$ & 18.21 \\
\hline \multicolumn{5}{|c}{ Table 3. Quality of Classification Results }
\end{tabular}

The best result (Table 3) is obtained by the GSO in the first area, whereas the lowest is by the LSO in the second area. The GSO led to a higher TP in both test areas compared to the LSO, which indicates that the GSO led to a larger overlap area between automated and manual delineation. However, the GSO also resulted in a higher FP and lower FN compared to the LSO. Although the quality of the classification is low, the first area resulted in a higher quality compared to the second area. This result is as we expected since the difference between slum and non-slum areas in the first area is clearer than in the second area. However, the lower accuracy achieved by the LSO is not as we expected. We expect that the LSO should have higher accuracies since the LSO represents the local ontology based on the local characteristics stressed by experts. We argue that the low accuracy values of the LSO be due to the smaller slum area extracted by the automated detection. The tenure status ${ }^{2}$ was added as a slum characteristic for the LSO (Table 2). We combined the results from confusion matrix-based accuracy and quality of classification. As shown in Figure 3, a transferable ruleset should lead to similar accuracies when applied to a different area. We calculate the difference of accuracy result between the first and the second area for each ontology. To make the graph easier to interpret, we inversed the values. Thus, the higher the value, the less different the accuracy between the first and the second area; the more transferable the ruleset. We visualised the result in Figure 9.

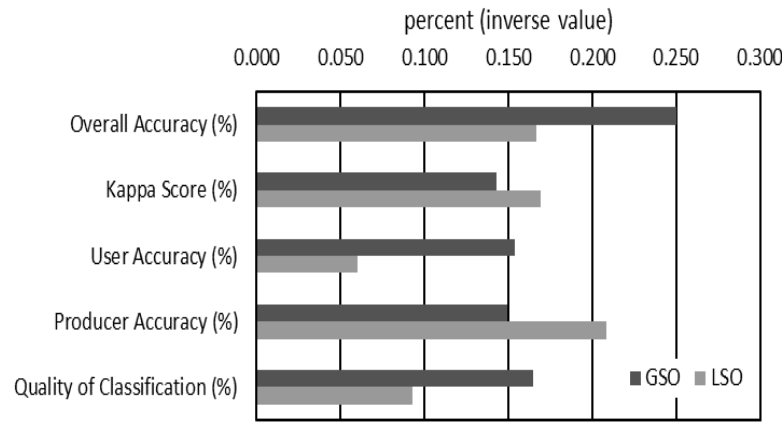

Figure 9. Spatial Transferability

According to Figure 9, the GSO resulted in higher transferability (lower difference of accuracies) for the three measurements, whereas the LSO shows a better Kappa and producer accuracy. Hence, the GSO is slightly more transferable than LSO. This result is unexpected since we assumed the local adaptation (LSO) would increase the accuracy of extracting slums.

\footnotetext{
2 Tenure status is obtained from the land use map. Developments are prohibited in green areas or buffer zones. Thus, by overlay the settlement with the land use data, we can indicate illegal settlements, which did not have a tenure status.
}

3.2.2 Temporal Transferability. For the first area, the GSO resulted in a slightly higher average of accuracy than the LSO, which is $70.8 \%$ and $70.4 \%$ respectively. Meanwhile for the second area, the LSO led to a higher average OA, which is $67.5 \%$. The average of the user accuracy obtained by the LSO in the first area is much greater compared to the GSO. For temporal transferability, the ruleset should result in a similar performance when applied to a different temporal image. Hence, we calculated the average of the accuracy changes. To make the comparison easier, we inversed the values (Figure 10). Thus, the higher the value, the less different the accuracy across the years; the more transferable the ruleset is.

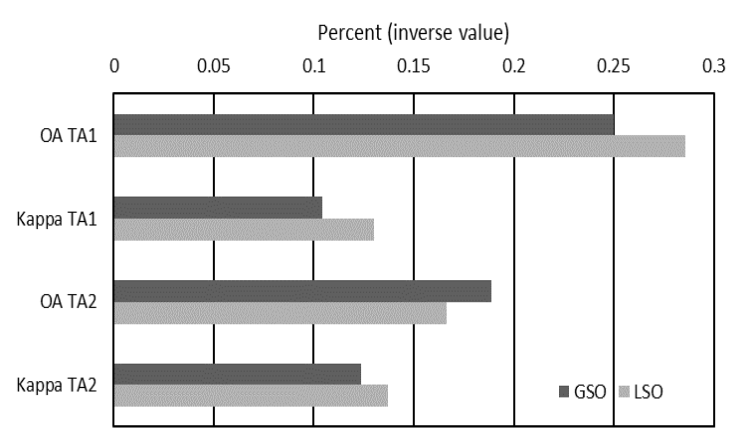

Figure 10. Temporal Transferability

For the first area, we can notice that the LSO produced a higher score (lower difference of accuracy across years) in three of four indicators. Meanwhile, in the second area, the GSO resulted in a higher score. Therefore, regarding temporal transferability, the LSO is more transferable to be applied in the first area, while the GSO is more transferable in the second area.

3.2.3 Spatiotemporal Transferability. The low values (Figure 11) indicate that the spatiotemporal results for the first and second area are similar; thus the ruleset is more transferable. Regarding Landscape Division, between 2012 and 2013 both rulesets are transferable. Meanwhile for 2014, both rulesets are more transferable to the first area, where in 2015 they are more transferable to the second area. For the Patch Density, both rulesets are transferable in both areas in 2012 and 2015. In addition, both rulesets are transferable in 2014 only for the first area. Regarding the Aggregation Index, GSO and LSO show good transferability for the second area. The Shannon's Evenness and Contagion Index resulted in similar patterns. Both of them indicated that both rulesets are not transferable. Firstly, the difference between rulesets is large in both test areas. A slightly smaller difference appeared in 2013 for the second test area. Secondly, the difference between GSO and LSO in both areas shows an increasing trend. 


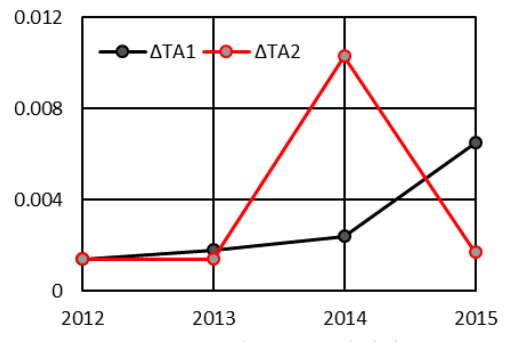

a. Landscape Division

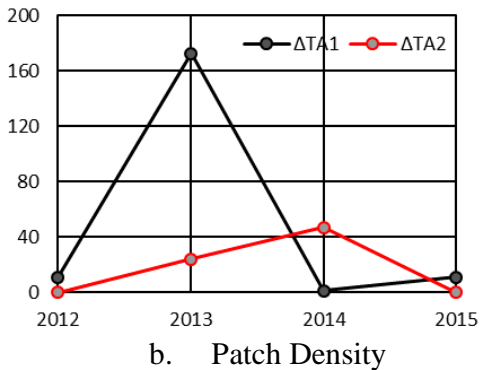

b. Patch Density

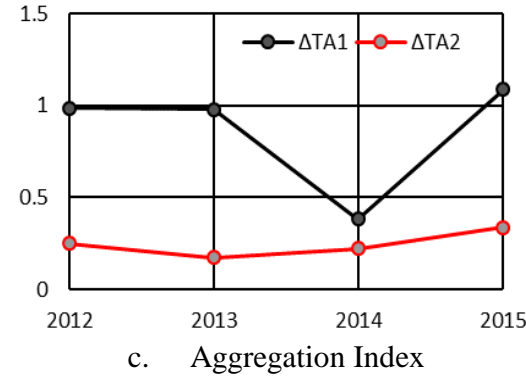

c. Aggregation Index

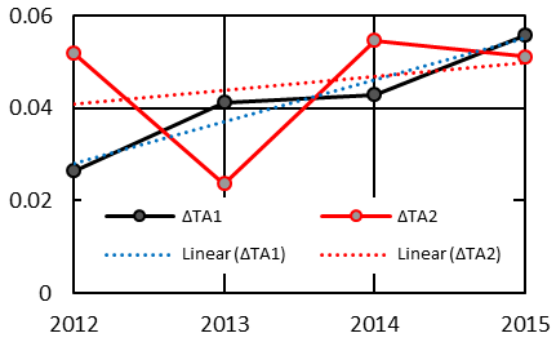

d. Shannon's Evenness Index

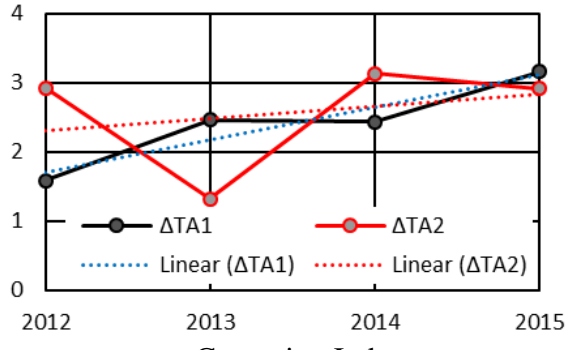

e. Contagion Index

Figure 11. Spatiotemporal Pattern

\subsection{Qualitative Measurement of Transferability}

3.3.1 Utility. Among eight real-world domain indicators from the GSO (Table 2), five of them can be used to detect slums in the study area. Meanwhile, three of them cannot be used due to different levels of aggregation, (e.g. distance to the economic hotspot) and unavailability of data (e.g. irregular road and small building size). Therefore, $62.5 \%$ of the GSO indicators can be used to detect slums. Meanwhile, from eight real-world domain indicators from the LSO (Table 2), only four of them $(50 \%)$ can be used to detect the slums. The reasons were the different levels of aggregation and unavailability of data. Therefore, the GSO is more transferable than LSO, in term of utility.

3.3.2 Generality. For the GSO, two adaptations are needed to detect the slums, which are the adaptation of NDVI values (for detecting vegetation), and the mean red/green ratio (for detecting the roof materials of slums). Meanwhile, since the LSO did not use the association to vegetation, the adaptation needed is only for roof materials. Therefore, in terms of generality, the LSO is more transferable compared to the GSO.

\section{CONCLUSIONS}

In measuring the spatial transferability, we conclude that the GSO resulted in a higher transferability compared to the LSO. This result is unexpected since we assumed that the local adaptation would increase the accuracy. We argue that the different perceptions on slum boundaries by the local experts that were used as reference caused this unexpected result (Figure 9). Furthermore, the usage of the tenure status as an indicator, which is not observable in an image, has affected the accuracy of the LSO since the reference data for the accuracy assessment are based on visual image interpretation by local experts. Therefore, the LSO resulted in a lower accuracy. Similar to the research of Kohli (2015), the reference from visual image interpretation introduces uncertainties since slums often have fuzzy boundaries and different ways to conceptualise. Similar with the temporal transferability, we expected that the LSO would show a higher transferability than the GSO in every area. However, the result shows the GSO had a higher temporal transferability in the first area. This result is unexpected. Three sources of uncertainties might explain this unexpected result. Firstly, the static concept and dynamic changes. As mentioned by Arvor et al. (2013), a real-world object changes over time, but the description of an object remains static in the ontology. For instance, we assumed the tenure status of a particular area did not change between 2012 and $2015^{3}$, but in the real world, this changed. Secondly, real world characteristics need to be translated into the image domain. Our knowledge of particular characteristics is often qualitative and subjective, but the information contained in an image is quantitative (Arvor et al., 2013). For instance, we argue that the lack of open green space be one characteristic of slums. This real world definition needs to be translated into the image domain. Although we applied different NDVI thresholds for different images, it is also possible that these thresholds do not capture the phenomenon sufficiently. For instance, during the dry season, leafs of trees are brown coloured. Lastly, similar due to the uncertainties in spatial transferability, the usage of tenure status also resulted in a low accuracy of the LSO. The result shows that assessing the transferability of slum detection methods across space, time and conceptualizations helps in detecting and understanding sources of uncertainties, which ultimately will support the development of more transferable and robust methods. A thorough understanding of uncertainties in slum mapping is essential for the development of policyrelevant information, such as the monitoring of large-scale slum improvement initiatives.

\section{ACKNOWLEDGEMENTS}

Multitemporal Pleiades imagery that was used in this research was obtained from the European Space Agency (ESA).

\footnotetext{
${ }^{3}$ Tenure status was obtained from the Land use Planning documents, which have a period of 20 years and are reviewed every 5 years
} 


\section{REFERENCES}

Arvor, D., Durieux, L., Andrés, S., \& Laporte, M. A. (2013). Advances in Geographic Object-Based Image Analysis with ontologies: A review of main contributions and limitations from a remote sensing perspective. ISPRS Journal of Photogrammetry and Remote Sensing, 82, 125-137. http://doi.org/10.1016/j.isprsjprs.2013.05.003

Baatz, M., \& Schäpe, A. (2000). Multiresolution Segmentation: an optimization approach for high quality multi-scale image segmentation. In Angewandte Geographische Informationsverarbeitung XII. Beiträge zum AGIT-Symposium Salzburg 2000, Karlsruhe, Herbert Wichmann Verlag (pp. 12 23). Retrieved

http://www.ecognition.cc/download/baatz_schaepe.pdf

Bamberger, M. (2012). Introduction To Mixed Methods in Impact Evaluation. Impact Evaluation Notes. Retrieved from http://www.interaction.org/sites/default/files/Mixed Methods in Impact Evaluation (English).pdf

Demographia. (2015). Demographia World Urban Areas (11th ed.). Demographia. Belleville. Retrieved from http://www.demographia.com/db-worldua.pdf

Department of Building and Settlements DKI. (2014). Pemetaan Direktori Kumuh [Directory of Slum Settlements]. Unpublished Manuscript, Jakarta.

Drăguţ, L., Tiede, D., \& Levick, S. R. (2010). ESP: a tool to estimate scale parameter for multiresolution image segmentation of remotely sensed data. International Journal of Geographical Information Science, 24(6), 859-871. http://doi.org/10.1080/13658810903174803

Groenendijk, E. M. C., \& Dopheide, E. J. M. (2003). Planning and management tools. ITC Special Lecture Notes Series. Enschede: The International Institute for Geo-Information Science and Earth Observation (ITC). Retrieved from http://www.itc.nl/library/Papers_2003/tech_rep/groenendijk.pdf

Harwell, M. R. (2011). Research Design in Qualitative/Quantitative/ Mixed Methods. In C. F. Conrad \& R. C. Serlin (Eds.), The SAGE Handbook for Research in Education (2nd ed., pp. 147-163). SAGE Publications Ltd.

Indonesian Central Board of Statistics (BPS). (2013). Indikator Rumah Tangga Kumuh [Slum Household Indicator]. Retrieved January 20, 2016, from http://sirusa.bps.go.id/index.php?r=indikator/view\&id=453

Kohli, D. (2015). Identifying and classifying slum areas using remote sensing. University of Twente. Retrieved from http://purl.org/utwente/doi/10.3990/1.9789036540087

Kohli, D., Kerle, N., \& Sliuzas, R. (2012). Local ontologies for object-based slum identification and classification. In Proceedings of the 4th GEOBIA (p. 201). Rio de Janeiro. Retrieved from https://www.researchgate.net/publication/230667153_Local_on tologies_for_object-

based_slum_identification_and_classification

Kohli, D., Sliuzas, R., Kerle, N., \& Stein, A. (2012). An ontology of slums for image-based classification. Computers, Environment and Urban Systems, 36(2), 154-163. http://doi.org/10.1016/j.compenvurbsys.2011.11.001

Kohli, D., Warwadekar, P., Kerle, N., Sliuzas, R., \& Stein, A. (2013). Transferability of object-oriented image analysis methods for slum identification. Remote Sensing, 5(9), 4209-
4228. http://doi.org/10.3390/rs5094209

Kuffer, M., Barros, J., \& Sliuzas, R. V. (2014). The development of a morphological unplanned settlement index using very-high-resolution (VHR) imagery. Computers, Environment and Urban Systems, 48, 138-152. http://doi.org/10.1016/j.compenvurbsys.2014.07.012

Kuffer, M., Pfeffer, K., \& Sliuzas, R. (2016). Slums from Space - 15 Years of Slum Mapping Using Remote Sensing. Remote Sensing, 8(6), 1-29. http://doi.org/10.3390/rs8060455

McKeown, D. M., \& Cochran, S. D. (1999). Fusion of HYDICE hyperspectral data with panchromatic imagery for cartographic feature extraction. IEEE Transactions on Geoscience and Remote Sensing, 37(3 I), 1261-1277. http://doi.org/10.1109/36.763286

Ministry of Public Works and Public Housing. (2014). Panduan Penyusunan SPPPIP dan RPKPP [Guideline for Urban Settlement and Infrastructure Development]. (Directorate of Settlement Development, Ed.) (5th ed.). Jakarta. Retrieved from http://www.scribd.com/doc/147120807/Buku-PanduanPenyusunan-SPPIP-dan-RPKPP\#scribd

Netzband, M. (2009). Physical Characterisation of Deprivation in Cities. In Urban Remote Sensing Event, 2009 Joint (pp. 1-5). Shanghai: IEEE. http://doi.org/10.1109/URS.2009.5137652

Pratomo, J. (2016). Transferability of The Generic and Local Ontology of Slum in Multi-temporal Imagery, Case Study: Jakarta. University of Twente. Retrieved from http://www.itc.nl/library/papers_2016/msc/upm/pratomo.pdf

Rukmana, D. (2008). Planning the Megacity: Jakarta in the Twentieth Century. Journal of the American Planning Association, 74(2), 263-264. http://doi.org/10.1080/01944360801940995

Sori, N. D. (2012). Identifying and Classifying Slum Development Stages from Spatial Data. University of Twente. Retrieved from https://www.itc.n1/library/papers_2012/msc/upm/dinsasori.pdf

Tuanmu, M.-N., Viña, A., Roloff, G. J., Liu, W., Ouyang, Z., Zhang, H., \& Liu, J. (2011). Temporal transferability of wildlife habitat models: implications for habitat monitoring. Journal of Biogeography, 38(8), $1510-1523$ http://doi.org/10.1111/j.1365-2699.2011.02479.x

UN-Habitat. (2014). Indonesia prepares National Report for Habitat III. Retrieved February 11, 2016, from $\mathrm{http}$ //unhabitat.org/indonesia-prepares-national-report-forhabitat-iii/

Whiteside, T. G., Boggs, G. S., \& Maier, S. W. (2011). Comparing object-based and pixel-based classifications for mapping savannas. International Journal of Applied Earth Observation and Geoinformation, 13(6), 884-893. http://doi.org/10.1016/j.jag.2011.06.008

Woodcook, C., \& Strahler, A. (1987). The factor of scale in remote sensing. Remote Sensing of Environment, 21, 311-332. http://doi.org/10.1016/0034-4257(87)90015-0 